\title{
Efficacy and safety of single high-dose versus double high-dose intracoronary bolus tirofiban in patients with ST-segment elevation myocardial infarction
}

\author{
Mehmet Kaplan $\odot$, İbrahim Halil Kurt $\odot$, Alaa Quisi $\odot$, Gökhan Alıcı๑, Şerafettin Demir $\odot$, Fethi \\ Yavuz $\odot$, Yurdaer Dönmez $\odot$
}

Department of Cardiology, University of Health Sciences, Adana City Training and Research Hospital, Adana, Turkey

\begin{abstract}
Objectives: We evaluated the efficacy and safety of single high-dose versus double high-dose intracoronary bolus tirofiban in patients with ST-segment elevation myocardial infarction (STEMI) undergoing primary percutaneous coronary intervention (PCI).

Methods: A total of 80 patients, who were admitted to our clinic and underwent primary PCI, were included in this observational cohort study. The patients were divided into the single high-dose group $(\mathrm{n}=40)$ and the double high-dose group $(n=40)$ according to the intracoronary bolus tirofiban regime. The primary endpoint was assumed as the incidence of major adverse cardiac event (s) (MACE) defined as all-cause mortality and repeat coronary revascularization (target vessel revascularization [TVR]) at 30 days. MACE and bleeding events were evaluated at 7 and 30 days.

Results: The primary endpoint was not significantly different between the single and the double high-dose groups $(40.0 \%$ vs. $17.5 \%, p=0.994)$. However, a significantly lower 30 -day TVR rate was observed in the double high-dose group (27.5\% vs. $7.5 \%, p=0.019)$. No significant difference was observed in terms of 30 day all-cause mortality between the two groups $(12.5 \%$ vs. $10.0 \%, p=0.712)$. Major bleeding events were not observed in any group. Multivariate logistic regression analysis demonstrated that CRUSADE score (Hazard ratio [HR]: $5.721 ; 95 \% \mathrm{CI}: 2.036$ to $16.073, p=0.001)$ and platelet count (HR: $1.009 ; 95 \% \mathrm{CI}: 1.000$ to 1.018 , $p=0.048$ ) were the independent predictors of bleeding at 7 days.

Conclusions: Double high-dose intracoronary bolus tirofiban in STEMI patients undergoing primary PCI was associated with significantly lower 30-day TVR rates without an increase in bleeding events. However, it did not significantly affect MACE and all-cause mortality rates.

Keywords: high-dose, glycoprotein IIb/IIIa receptor inhibitor, tirofiban, ST-segment elevation myocardial infarction, efficacy, safety
\end{abstract}

T-seg (STE
tion, which
coronary
conseque T-segment elevation myocardial infarction (STEMI) is a potentially life-threatening condition, which usuallyoccurs as a result ofa vulnerable coronary plaque rupture and thrombus formation, andconsequently leads to an acute reduction inmyocardial blood flowand subsequentmyocardial necrosis.However, Itsometimesmanifests as sudden cardiac arrest due to ischemia-induced tachyarrhythmia. It is noteworthy that the incidence of STEMI is declining [1, 2], possibly due to the reduction in smoking, the aging 
of the population, and the prevalent use of statin therapy. Similar trends have been suggested for sudden cardiac arrest. Primary percutaneous coronary intervention (PCI) is the preferred approach for early restoration of myocardial blood flow in the infarct-related artery in patients with STEMI [3]. In addition, a combination of anti-ischemic, antiplatelet and antithrombotic therapies is indispensable.

Tirofiban is a highly selective anda short-acting platelet glycoprotein (GP) IIb/IIIa receptor inhibitor,which inhibits platelet aggregation by blocking the combination of fibrinogen and GP IIb/IIIa and consequently prevents myocardial ischemia caused by coronary thrombosis [4, 5]. Regarding tirofiban dosage, unlike the trials of low-dose bolus regimens [6-9], recent studies involving the high-dose bolus regimen support its efficacy in patients with STEMI undergoing primary PCI [10-12]. These results may translate to clinical benefit while not significantly increasing bleeding complications. Not only the optimal doses but also the ideal route of administration of GP $\mathrm{IIb} / \mathrm{III}$ receptor inhibitors has also been actively investigated $[13,14]$. A previous study demonstrated that the standard intravenous tirofiban bolus plus infusion strategy was not superior to an intracoronary tirofiban bolus-only strategy with respect to improvement of microvascular perfusion after primary PCI [15]. In this study, we aimed to evaluate the efficacy and safety of single high-dose versus double high-dose intracoronary bolus tirofiban in STEMI patients undergoing primary PCI.

\section{METHODS}

\section{Study Population and Design}

This single-center, observational cohort study included a total of 80 patients, who were diagnosed with STEMI and underwent primary PCI within $12 \mathrm{~h}$ of the onset of symptoms at our cardiology clinic between January 2016 and June 2016. All patients meeting the inclusion criteria were included into the study consecutively. İnformed written consent was obtained from all patients. Data of the patients were obtained from file archives and catheter laboratory records.

The patients in the groups were in accordance with the current guidelines for the indication of tirofiban. The study population was divided into two groups by sequence number; the single high-dose group $(n=40)$ and the double high-dose group $(n=40)$. Depending on the sequence number, in the single high-dose group, tirofiban $25 \mathrm{mcg} / \mathrm{kg}$ via intracoronary route within $3 \mathrm{~min}$ followed by $0.15 \mathrm{mcg} / \mathrm{kg} / \mathrm{min}$ via intravenous route for up to $24 \mathrm{~h}$ was administered, whereas in the double high-dose group, tirofiban 25 $\mathrm{mcg} / \mathrm{kg}$ was administered within $3 \mathrm{~min}$ followed by a second dose after $5 \mathrm{~min}$ and $0.15 \mathrm{mcg} / \mathrm{kg} / \mathrm{min}$ via intravenous route for up to 24 hour.Other medications were administered to all the patients according to the current best clinical practice: aspirin (loading dose of $300 \mathrm{mg}$, then $100 \mathrm{mg} \mathrm{qd}$ ), clopidogrel (loading dose of $600 \mathrm{mg}$, then $75 \mathrm{mg} \mathrm{qd})$, heparin $(40-70 \mathrm{U} / \mathrm{kg}$ ) or low molecular weight heparin, angiotensin-converting enzyme inhibitor (ACEI) or angiotensin II receptor blocker (ARB), $\beta$-blocker, and statin therapy.

Patients with acute/chronic infective or inflammatory disease, severe heart valve disease, severe congestive heart failure (left ventricular ejection fraction (LVEF) $<30 \%$ ), chronic kidney disease (glomerular filtration rate $<90 \mathrm{~mL} / \mathrm{min} / 1.73$ $\mathrm{m} 2$ ), chronic liver disease and Killip class 3-4 were not included. The Institutional Ethics Committee approved the study protocol.

Data concerning cardiovascular risk factors, including age, gender, hypertension (HT), diabetes mellitus (DM), hyperlipidemia (HPL), and smoking status were noted. Venous blood samples to measure complete blood count, lipid panel, high-sensitivity cardiac troponin $\mathrm{T}$ (hs-cTnT), creatinine, and highsensitivity C-reactive protein (hs-CRP) levels were obtained from all the patients on admission. Routine blood chemistry and lipid panel parameters were measured with a standard auto-analyzer. Blood counts were measured with a Sysmex K-1000 (Block Scientific, Bohemia, New York, USA) auto-analyzer within 5 min of sampling. Serum concentrations of hscTnT were measured using an Elecsys 2010 analyzer (Cobas e 411; Elecsys, Roche Diagnostics, Mannheim, Germany). Serum concentrations of hs-CRP levels were measured using an automated chemistry analyzer by a commercial kit (Abbott, Aeroset, Holliston, Minn.).

Coronary intervention procedures were performed using commercially available Siemens (Axiom Sensis XP, Berlin, Germany) and Toshiba (Infinix CSI,Tokyo, 
Japan) devices viafemoral access and standard techniques. Angiographic features, including initial TIMI flow, TIMI flow after tirofiban administration, final TIMI flow after PCI, no-reflow phenomenon, initial TIMI thrombus grade, and TIMI thrombus grade after tirofiban administration were evaluated by two blinded interventional cardiologists. The diagnosis of the no-reflow phenomenon was made when postprocedural TIMI flow grade is $<3$, or in the case of a TIMI flow grade of 3 when myocardial blush grade is 0 or 1 , or when ST resolution within $4 \mathrm{~h}$ of the procedure is $<70 \%$ [16]. Coronary thrombus was graded according to the TIMI thrombus scale [17]. Patients were followed up for 30 days for major adverse cardiovascular event (s) (MACE) and target vessel revascularization (TVR). All datas were recorded and there were no missing data. The cause of deaths were all cardiac, especially ventricular arrhythmia.

\section{Clinical Endpoints and Definitions}

Data regarding clinical end points were obtained from the health information system of our institute and the national health registry. No study-specific clinical follow-up was done. The primary endpoint was defined as the incidence of MACE defined as all-cause mortality and repeat coronary revascularization (target vessel revascularization [TVR]) at 30 days. TVR was defined as any revascularization procedure for stent thrombosis or in-stent restenosis, including bypass surgery, involving the initially treated artery. MACEs were evaluated at 7 and 30 days.Major bleeding was defined as an intracranial bleeding or a decrease in the hemoglobin concentration of $5 \mathrm{~g} / \mathrm{dL}$ or more or a decrease in hematocrit of $15 \%$ or more. The CRUSADE (Can Rapid risk stratification of Unstable angina patients Suppress Adverse outcomes with Early implementation of the American College of Cardiology / American Heart Association guidelines) score to stratify baseline risk of major bleeding was calculated. Bleeding was considered minor if the hemoglobin concentration decreased by $<5 \mathrm{~g} / \mathrm{dL}$ or the hematocrit decreased by $<15 \%$ [18]. Bleeding events were evaluated at 7 and 30 days.

\section{Statistical Analysis}

Data analyses were performed using SPSS statistical software package version 20.0 (Chicago, IL, USA).
Continuous variables were expressed as mean \pm standard deviation and median and interquartile range as appropriate. Categorical variables were expressed as numberand percentage. The normal distribution of continuous variables was assessed using the Kolmogorov-Smirnov test. Comparison of continuous variables between groups was performed using the Independent-Samples T test and the MannWhitney $U$ test as appropriate. Comparison of categorical variables between groups was performed using the Chi-Square test and the Fisher's Exact test as appropriate. The correlation between certain variables of the treatment groups was performed using the Spearman's rank-order correlations analysisand the Pearson product-moment correlation analysis as appropriate. All significant parameters $(p<0.01)$ in the univariate analysis were selected for the multivariate model and forward stepwise multivariate logistic regression analysis was used to determine the independent predictors of bleeding at 7 days. The coefficient of regression and $95 \%$ confidence interval for each independent variable were calculated. The 30day event-free survival curves were constructed using the Kaplan-Meier method and statistical differences between curves were assessed by the log-rank test. The hazard ratio for treatment comparisons was estimated using Cox proportional hazard models. A two-tailed $p$ - value of less than 0.05 was considered as significant.

\section{RESULTS}

A total of 80 patients (57 men and 23 women; mean age: $59.4 \pm 10.4$ years), who were diagnosed with STEMI and underwent primary PCI were included. The patients were divided into the single high-dose group $(n=40)$ and the double high-dose group $(n=40)$ regarding tirofiban dose. Baseline characteristics of the patients were similar in the two groups except in terms of gender and serum creatinine levels (Table 1).

Angiographic and procedural characteristics of the patients were similar in the two groups except in terms of the initial TIMI flow, TIMI flow after tirofiban administration and stent length (Table 2). Regarding the initial TIMI flow, proportions of patients with grade $0,1,2$, and 3 in the single high-dose group were 
Table 1. Baseline characteristics of the patients

\begin{tabular}{|c|c|c|c|}
\hline Variable & $\begin{array}{c}\text { Single } \\
\text { high-dose group } \\
(\mathrm{n}=\mathbf{4 0})\end{array}$ & $\begin{array}{c}\text { Double } \\
\text { high-dose group } \\
(\mathrm{n}=\mathbf{4 0})\end{array}$ & $p^{\text {a }}$ value \\
\hline Age (years) & $59.2 \pm 9.7$ & $59.7 \pm 11.2$ & 0.807 \\
\hline Gender, (male), n (\%) & $24(60.0)$ & $33(82.5)$ & 0.026 \\
\hline HT, n (\%) & $11(27.5)$ & $14(35.0)$ & 0.605 \\
\hline DM, n (\%) & $6(15.0)$ & $7(17.5)$ & 0.501 \\
\hline HPL, n (\%) & $9(22.5)$ & $10(25.0)$ & 0.523 \\
\hline Current smoker, n (\%) & $10(25.0)$ & $12(30.0)$ & 0.766 \\
\hline CAD, n (\%) & $4(10.0)$ & $4(10.0)$ & $-\mathrm{b}$ \\
\hline CABG, n (\%) & $2(5.0)$ & $0(0.0)$ & 0.423 \\
\hline COLD, n (\%) & $1(2.5)$ & $1(2.5)$ & $-b$ \\
\hline Hemoglobin (g/dL) & $13.0 \pm 2.1$ & $13.1 \pm 2.2$ & 0.679 \\
\hline $\mathbf{W B C}, \times 10^{3} / \mathbf{u L}$ & $\begin{array}{c}11.9 \pm 4.9 \\
10.25(8.8-14.6)\end{array}$ & $\begin{array}{c}11.0 \pm 4.5 \\
9.5(8.2-14.5)\end{array}$ & 0.285 \\
\hline Hematocrit (\%) & $39.6 \pm 6.0$ & $41.0 \pm 5.2$ & 0.284 \\
\hline Platelet count, $\times 10^{3} / \mathrm{uL}$ & $\begin{array}{c}285.6 \pm 74.6 \\
269(230.5-336.8)\end{array}$ & $\begin{array}{c}287.3 \pm 85.0 \\
277(222-321)\end{array}$ & 0.992 \\
\hline Creatinine (mg/dL) & $\begin{array}{c}0.8 \pm 0.3 \\
0.8(0.6-1.0)\end{array}$ & $\begin{array}{c}0.9 \pm 0.3 \\
0.9(0.8-1.1)\end{array}$ & 0.010 \\
\hline Triglyceride (mg/dL) & $\begin{array}{c}202.5 \pm 120.6 \\
200(96-266.8)\end{array}$ & $\begin{array}{l}208.5 \pm 111.7 \\
212(92-279)\end{array}$ & 0.573 \\
\hline Total cholesterol (mg/dL) & $\begin{array}{c}213.1 \pm 58.4 \\
209.5(174.3-245.3)\end{array}$ & $\begin{array}{c}205.0 \pm 42.6 \\
202(184-237)\end{array}$ & 0.456 \\
\hline HDL cholesterol (mg/dL) & $\begin{array}{l}36.5 \pm 7.9 \\
33(30-43)\end{array}$ & $\begin{array}{l}39.1 \pm 10.7 \\
39(32-44)\end{array}$ & 0.296 \\
\hline LDL cholesterol (mg/dL) & $\begin{array}{c}148.8 \pm 55.2 \\
138(127.3-158.5)\end{array}$ & $\begin{array}{c}143.4 \pm 27.6 \\
145(128-160)\end{array}$ & 0.627 \\
\hline hs-CRP (mg/dL) & $\begin{array}{c}2.3 \pm 2.9 \\
1.8(0.4-3.4)\end{array}$ & $\begin{array}{c}2.5 \pm 2.2 \\
1.6(0.8-3.7)\end{array}$ & 0.324 \\
\hline hs-cTnT (ng/mL) & $\begin{array}{c}3.1 \pm 3.1 \\
2.2(0.76-4.2)\end{array}$ & $\begin{array}{c}3.1 \pm 3.3 \\
1.7(0.75-4)\end{array}$ & 0.722 \\
\hline LV ejection fraction (\%) & $46.1 \pm 11.7$ & $48.5 \pm 7.0$ & 0.261 \\
\hline \multicolumn{4}{|l|}{ CRUSADE risk category, $n(\%)$} \\
\hline Very low $($ score $\leq 20)$ & $6(15.0)$ & $8(20.0)$ & \\
\hline Low (score 21-30) & $11(27.5)$ & $14(35.0)$ & \\
\hline Moderate (score 31-40) & $14(35.0)$ & $8(20.0)$ & 0.359 \\
\hline High (score 41-50) & $8(20.0)$ & $6(15.0)$ & \\
\hline Very high $(>50)$ & $1(2.5)$ & $4(10.0)$ & \\
\hline \multicolumn{4}{|l|}{ Cardiovascular drugs, n (\%) } \\
\hline Clopidogrel & $40(100.0)$ & $40(100.0)$ & $-\mathrm{b}$ \\
\hline Aspirin & $40(100.0)$ & $40(100.0)$ & $-b$ \\
\hline$\beta$ blocker & $38(95.0)$ & $37(92.5)$ & 0.228 \\
\hline Statin & $40(100.0)$ & $40(100.0)$ & $-\mathrm{b}$ \\
\hline ACE-I/ARB & $40(100.0)$ & $40(100.0)$ & $-\mathrm{b}$ \\
\hline
\end{tabular}

Data are presented as number (percentage) or mean \pm standard deviation or median (interquartile range). $\mathrm{HT}=$ Hypertension, $\mathrm{DM}=$ Diabetes mellitus, $\mathrm{HPL}=$ Hyperlipidemia, $\mathrm{CAD}=$ Coronary artery disease, $\mathrm{CABG}=$ Coronary artery bypass grafting, $\mathrm{COLD}=$ Chronic obstructive lung disease, $\mathrm{WBC}=$ White blood cell, $\mathrm{HDL}=$ High-density lipoprotein, LDL = Low-density lipoprotein, hs-CRP = High-sensitivity C-reactive protein, hs-cTnT $=$ High-sensitivity cardiac troponin $\mathrm{T}, \mathrm{LV}=$ Left ventricle, CRUSADE $=$ Can Rapid risk stratification of Unstable angina patients Suppress ADverse outcomes with Early implementation of the ACC/AHA guidelines, ACEI = Angiotensin converting enzyme inhibitor, ARB: Angiotensin receptor blocker

${ }^{a}$ Independent-Samples T test, Chi-Square test, Mann-Whitney U test.

bNo statistics are computed becasue the variable is a constant. 
Table 2. Angiographic and procedural characteristics

\begin{tabular}{|c|c|c|c|}
\hline Variable & $\begin{array}{c}\text { Single } \\
\text { high-dose group } \\
(\mathrm{n}=\mathbf{4 0})\end{array}$ & $\begin{array}{c}\text { Double } \\
\text { high-dose group } \\
(n=40)\end{array}$ & $p^{\mathrm{a}}$ value \\
\hline \multicolumn{4}{|l|}{ Culprit vessel, n (\%) } \\
\hline LAD & $15(37.5)$ & $20(50.0)$ & \\
\hline $\mathrm{LCx}$ & $9(22.5)$ & $8(20.0)$ & \\
\hline $\mathrm{RCA}$ & $13(32.5)$ & $11(27.5)$ & \\
\hline IM & $2(5.0)$ & $1(2.5)$ & \\
\hline SVG & $1(2.5)$ & $0(0.0)$ & \\
\hline One vessel disease, n (\%) & $24(60.0)$ & $21(52.5)$ & 0.423 \\
\hline Multi-vessel disesase, $n(\%)$ & $16(40.0)$ & $19(47.5)$ & 0.374 \\
\hline Mean ischemic time (min) & 56 & 61 & 0.459 \\
\hline Killip class 1 & 21 & 18 & 0.562 \\
\hline Killip class 2 & 19 & 22 & 0.378 \\
\hline Balloon pre-dilatation, n (\%) & $24(60.0)$ & $27(67.5)$ & 0.485 \\
\hline Balloon post-dilatation, n (\%) & $17(42.5)$ & $9(22.5)$ & 0.056 \\
\hline No-Reflow, n (\%) & $29(72.5)$ & $25(62.5)$ & 0.363 \\
\hline Thrombus aspiration, n (\%) & $11(27.5)$ & $11(27.5)$ & $-\mathrm{b}$ \\
\hline \multicolumn{4}{|l|}{ Initial TIMI flow, n (\%) } \\
\hline Grade 0 & $12(30.0)$ & $16(40.0)$ & \\
\hline Grade 1 & $16(40.0)$ & $10(25.0)$ & \\
\hline Grade 2 & $12(30.0)$ & $12(30.0)$ & \\
\hline Grade 3 & $0(0.0)$ & $2(5.0)$ & \\
\hline \multicolumn{4}{|l|}{ TIMI flow after Tirofiban, n (\%) } \\
\hline Grade 0 & $8(20.0)$ & $6(15.0)$ & \\
\hline Grade 1 & $13(32.5)$ & $8(20.0)$ & \\
\hline Grade 2 & $14(35.0)$ & $17(22.5)$ & \\
\hline Grade 3 & $5(12.5)$ & $9(22.5)$ & \\
\hline \multicolumn{4}{|l|}{ Final TIMI flow after PCI, n (\%) } \\
\hline Grade 0 & $4(10.0)$ & $2(5.0)$ & \\
\hline Grade 1 & $11(27.5)$ & $8(27.5)$ & \\
\hline Grade 2 & $14(35.0)$ & $16(40.0)$ & \\
\hline Grade 3 & $11(27.5)$ & $14(35.0)$ & \\
\hline Stent diameter $(\mathrm{mm})$ & $\begin{array}{c}3.0 \pm 0.5 \\
3.0(2.75-3)\end{array}$ & $\begin{array}{c}3.0 \pm 0.4 \\
3.0(2.75-3)\end{array}$ & 0.682 \\
\hline Stent length (mm) & $\begin{array}{l}24.9 \pm 8.6 \\
24(18-28)\end{array}$ & $\begin{array}{c}21.2 \pm 10.2 \\
19(16-24)\end{array}$ & 0.005 \\
\hline \multicolumn{4}{|l|}{ Stent type, n (\%) } \\
\hline DES & $30(75.0)$ & $27(67.5)$ & 0.459 \\
\hline BMS & $10(25.0)$ & $13(32.5)$ & \\
\hline \multicolumn{4}{|c|}{ Initial TIMI thrombus grade, $n(\%)$} \\
\hline Grade 1 & $5(12.5)$ & $4(10.0)$ & \\
\hline Grade 2 & $22(55.0)$ & $18(45.0)$ & \\
\hline Grade 3 & $12(30.0 \%)$ & $12(30.0)$ & \\
\hline Grade 4 & $1(2.5)$ & $5(12.5)$ & \\
\hline Grade 5 & $0(0.0)$ & $1(2.5)$ & \\
\hline \multicolumn{4}{|c|}{ TIMI thrombus grade after Tirofiban, $\mathbf{n}(\%)$} \\
\hline Grade 1 & $11(27.5)$ & $14(35.0)$ & \\
\hline Grade 2 & $18(45.0)$ & $14(45.0)$ & \\
\hline Grade 3 & $10(25.0)$ & $8(20.0)$ & \\
\hline Grade 4 & $1(2.5)$ & $4(10.0)$ & \\
\hline Grade 5 & $0(0.0)$ & $0(0.0)$ & \\
\hline
\end{tabular}

Data are presented as number (percentage) or mean \pm standard deviation or median (interquartile range). LAD $=$ Left anterior descending artery, $\mathrm{LCx}=$ Left circumflex artery, RCA $=$ Right coronary artery, $\mathrm{IM}=$ Intermediate artery, $\mathrm{SVG}=$ Saphenous vein graft, $\mathrm{MI}=$ Myocardial Infarction, DES $=$ Drug-eluting stent, BMS $=$ Bare-metal stent, TIMI = Thrombolysis In Myocardial Infarction, PCI = Percutaneous coronary intervention ${ }^{a}$ Chi-Square test, Mann-Whitney U test.

bNo statistics are computed becasue the variable is a constant 
Table 3. Clinical events at 7 and 30 days

\begin{tabular}{|c|c|c|c|c|}
\hline & $\begin{array}{c}\text { Single } \\
\text { high-dose group } \\
(\mathrm{n}=\mathbf{4 0})\end{array}$ & $\begin{array}{c}\text { Double } \\
\text { high-dose group } \\
(n=40)\end{array}$ & HR (95\% CI) & $p^{\text {a }}$ value \\
\hline \multicolumn{5}{|c|}{ MACE at 7 days, n (\%) } \\
\hline TVR & $6(15.0)$ & $3(7.5)$ & $\begin{array}{c}0.387 \\
(0.077-1.938)\end{array}$ & 0.206 \\
\hline Death & $2(5.0)$ & $2(5.0)$ & $\begin{array}{c}0.296 \\
(0.027-3.274)\end{array}$ & 0.291 \\
\hline Total & $8(20.0)$ & $5(12.5)$ & $\begin{array}{c}0.478 \\
(0.124-1.729)\end{array}$ & 0.195 \\
\hline \multicolumn{5}{|c|}{ MACE at 30 days, n (\%) } \\
\hline TVR & $11(27.5)$ & $3(7.5)$ & $\begin{array}{c}0.186 \\
(0.037-0.945)\end{array}$ & 0.019 \\
\hline Death & $5(12.5)$ & $4(10.0)$ & $\begin{array}{c}0.756 \\
(0.171-3.342)\end{array}$ & 0.712 \\
\hline Total & $16(40.0)$ & $7(17.5)$ & $\begin{array}{c}0.997 \\
(0.381-2.605)\end{array}$ & 0.994 \\
\hline
\end{tabular}

Data are presented as number (percentage). $\mathrm{HR}=$ Hazard ratio, $\mathrm{CI}=$ Confidence interval, MACE $=$ Major adverse cardiac event(s), TVR $=$ Target vessel revascularization.

${ }^{a}$ Log-Rank test.

$30.0 \%, 40.0 \%, 30.0 \%$ and $0.0 \%$, respectively, and in the double high-dose group they were $40.0 \%, 25.0 \%$, $30.0 \%$ and $5.0 \%$, respectively. Nevertheless, the proportion of patients with TIMI flow grade 2 after tirofiban administration was higher in the double highdose group than in the single high-dose group. In addition, it is noteworthy that there wasmorepatients with TIMI flow grade 0-1-2 ( noreflow) in the single high-dose group after tirofiban administration. Moreover, shorter stentswere deployed in the double high-dose group than in the single high-dose group ( $p$ $=0.005$ ).

According to the Kaplan-Meier analysis, the primary endpoint was not significantly different

Table 4. Bleeding events at 7 and 30 days

\begin{tabular}{cccc}
\hline & $\begin{array}{c}\text { Single } \\
\text { high-dose group } \\
(\mathbf{n}=\mathbf{4 0})\end{array}$ & $\begin{array}{c}\text { Double } \\
\text { high-dose group } \\
(\mathbf{n}=\mathbf{4 0})\end{array}$ & $p^{\mathrm{a}}$ value \\
\hline Bleeding at $\mathbf{7}$ days, $\mathbf{n}(\%)$ & $5(12.5)$ & $5(12.5)$ & $-{ }^{\mathrm{b}}$ \\
Minor & $0(0.0)$ & $0(0.0)$ & $-{ }^{\mathrm{b}}$ \\
Major & & $6(15.0)$ & 0.390 \\
Bleeding at $\mathbf{3 0}$ days, $\mathbf{n}(\%)$ & $9(22.5)$ & $0(0.0)$ & $-{ }^{\mathrm{b}}$ \\
\hline Minor & $0(0.0)$ & & \\
\hline Major & & & \\
\hline
\end{tabular}

Data are presented as number (percentage).

${ }^{\mathrm{a} C h i-S q u a r e ~ t e s t . ~}$




between the two groups (single high-dose group: $\mathrm{n}=$ $16(40.0 \%)$ vs. double high-dose group: $\mathrm{n}=7(17.5 \%)$; hazard ratio (HR): 0.997 (95\% confidence interval [CI]: 0.381 to 2.605 ); log-rank test $p=0.994$. However, analysis of the two main components of MACE revealed a significantly lower 30-day TVR rate in the double high-dose group (single high-dose group: $\mathrm{n}=11[27.5 \%$ ] vs. double high-dose group: $\mathrm{n}$ $=3$ [7.5\%]; HR: 0.186 [95\% CI: 0.037 to 0.945$]$; logrank test $p=0.019$ ) and a similar 30-day all-cause mortality rate in the two groups (single high-dose group: $\mathrm{n}=5[12.5 \%]$ vs. double high-dose group: $\mathrm{n}=$
4 [10.0\%]; HR: 0.756 [95\% CI: 0.171 to 3.342 ]; logrank test $p=0.712$ ). Clinical events at 7 and 30 days are shown in Table 3.

There was no major bleeding in both groups. Minor bleeding occurred in $12.5 \%$ of the patients in each group at 7-day. Bleeding events at 7 and 30 days are shown in table 4. Forward stepwise multivariate logistic regression analysis demonstrated that CRUSADE score (HR: 5.721; 95\% CI: 2.036 to $16.073, p=0.001)$ and platelet count (HR: $1.009 ; 95 \%$ CI: 1.000 to $1.018, p=0.048$ ) were the independent predictors of bleeding at 7 days (Table 5).

Table 5. Independent predictors of bleeding at 7 days

\begin{tabular}{lccccc}
\hline & \multicolumn{2}{c}{ Univariate Model } & \multicolumn{3}{c}{ Multivariate Model } \\
& $\begin{array}{c}\text { Correlation } \\
\text { coefficient }\end{array}$ & $\boldsymbol{p}$ value & HR & $\mathbf{9 5 \%}$ CI & $\boldsymbol{p}$ value \\
\hline Age & 0.332 & $\mathbf{0 . 0 0 3}$ & - & - & - \\
CRUSADE score & 0.484 & $<\mathbf{0 . 0 0 1}$ & 5.721 & $2.036-16.073$ & $\mathbf{0 . 0 0 1}$ \\
\hline Plasma hemoglobin level & -0.220 & 0.052 & - & - & - \\
Platelet count & 0.192 & 0.090 & 1.009 & $1.000-1.018$ & $\mathbf{0 . 0 4 8}$ \\
Serum creatinine level & 0.271 & $\mathbf{0 . 0 1 6}$ & - & - & - \\
\hline
\end{tabular}

$\mathrm{HR}=$ Hazard ratio, $\mathrm{CI}=$ Confidence interval, CRUSADE = Can Rapid risk stratification of Unstable angina patients Suppress ADverse outcomes with Early implementation of the ACC/AHA guidelines

\section{DISCUSSION}

The substantial finding of our study is that, administration of double high-dose intracoronary bolus tirofiban in STEMI patients undergoing primary PCI, in addition to aspirin, heparin, and high-dose clopidogrel, wasassociated with lower 30-day TVR rates without leading to a significant increase in minor or major bleeding.However, it did not significantly affect MACE and all-cause mortality rates. Unlike the trials involved low-dose bolus regimens [6-9], studies involving the high-dose bolus regimen of tirofiban support its efficacy and safety in patients with STEMI undergoing primary PCI [10-12]. To the best of our knowledge, this is the first study in the literature comparing the efficacy and safety of the single highdose versus double high-dose intracoronary bolus tirofiban in patients undergoing primary PCI.

Despite the considerable progress that has been made recently regarding the treatment of STEMI, including modern antithrombotic therapy, thrombus aspiration, and drug-eluting stents, questions have been raised concerning the potential benefit of GP IIb/IIIa receptor inhibitor in this setting. Several studies have demonstrated that despite these treatments events associated with thrombotic occlusion during or after PCI may still occur in 4$12.8 \%$ of the patients, and in high-risk patients, these events occur more often $[19,20]$. Tirofibanis a potent, competitive and inhibitor GP IIb/IIIawith a high specificity and affinity for the GP IIb/IIIa receptor [21]. It is a small and nonpeptide tyrosine derivative that dissociates from the GP IIb/IIIa receptor relatively rapidly, with a half-life of 2-4 hours, and its action is therefore reversed within hours after the completion of the infusion [22]. Such reversibility may have significant implications with regard to bleeding, particularly in patients who are considered for 
emergent cardiacsurgery.

The utility of tirofiban in patients with STEMI has been investigated in several trials $[6,10,11,23-25]$. These studies have evaluated both the $10 \mathrm{mcg} / \mathrm{kg}$ bolus and the high-dose bolus regimens. Administration of GP IIb/IIIa receptor inhibitors for bail-out therapy where there is an angiographic evidence of massive thrombus, slow or no-reflow or a thrombotic complication in patients with STEMI is a class IIa indication according to the diary guideline of the European Society of Cardiology [26]. Large studies show that in the real-world practice, GP $\mathrm{IIb} / \mathrm{III}$ receptor inhibitors are approximately given to $25-30 \%$ of patients with STEMI, often for bail-out situations [27, 28]. However, they should not be always restricted to patients with complications after PCI, even in the setting when high-dose clopidogrel isalready given in advance of PCI because the maximum antiplatelet effect of $600 \mathrm{mg}$ clopidogrel is achieved only after 2-4 h. Recent studies suggest that the high-bolus dose of tirofiban results in optimum platelet aggregation in most patients very early after PCI [23, 29]. Early administration of GP IIb/IIIa receptor inhibitors has actually attributed to the improvement in post-procedural myocardial perfusion and reduction in clinical outcomes, including death and cardiogenic shock $[30,31]$.

The results of several studiesinvolving early administration of tirofiban in patients undergoing primary PCI utilizing the $10 \mathrm{mcg} / \mathrm{kg}$ bolus regimen have suggested potential benefitsregardingthe restoration ofblood flow in the infarct-related artery and myocardial perfusion, although no improvement was found in clinical outcomes $[6-8,32]$.The OnTIME 2 trial [11], was the first study to determine the benefits of pre-hospital administration of tirofiban utilizing high-dose bolus regimen in addition to dual antiplatelet therapy measured by ST-segment deviation resolution. In this study, mean residual ST deviation before PCI and $1 \mathrm{~h}$ after PCI was significantly lower in patients pretreated with highbolus dose tirofiban than in those given placebo. Although, the rate of major bleeding did not differ significantly between the two groups. In addition, the results of 30-day follow-up demonstrated a significant benefit favoring tirofiban regarding the combined incidence of death, recurrent myocardial infarction, urgent TVR or thrombotic bailout. Moreover, further analysis suggested a relationship between the level of residual ST-segment deviation and mortality. Thus, On-TIME 2 trial has demonstrated a benefit of highdose bolus regimen of tirofiban over placebo with respect to clinical outcomes. Indeed the results of our study concerning TIMI flow before PCI and TVR rates at 30 days favoring not only the high-dose bolus regimen of tirofiban but also highlighting the potential benefits of double high-dose bolus regimen, without an increase in bleeding events.

In our study, triple antiplatelet therapy, with double high-dose bolus regimen of tirofiban, high-dose clopidogrel $(600 \mathrm{mg})$ and aspirin pretreatment was not associated with an increased risk of major bleeding. This finding might be related to a very careful heparindose protocol at our catheterization laboratory where we only give extra heparin during complex PCI procedures which exceed 1 hour in duration. Furthermore, low-molecular-weight heparin was directly discouraged after completion of the tirofiban infusion except for patients with atrial fibrillation and prosthetic heart valve with an international normalized ratio less than 2 .

Agents inhibiting platelet functions would be associated with an increased risk of bleeding. As it is well known, bleeding complications in patients undergoing PCI have been associated with an increased morbidity and mortality [33]. Therefore, preventing excessive bleeding is critical. Although it has been suggested that early initiation of a GP IIb/IIIa receptor inhibitor in patients with acute coronary syndrome may lead to an increase in bleeding [34], this was not observed in either the On-TIME 1 or the On-TIME 2 trials. Nevertheless, the results of OnTIME 2 trial revealed that there was no excess in major bleeding, even in patients receiving pre-hospital high-dose bolus tirofiban in addition to high-dose clopidogrel.

In our study, the rate of target vessel revascularization (TVR) at 30 days looks very high $(27.5 \%)$ in the single high-dose group, because noreflow was more in single high-dose group, stent length was longer in single high-dose group. We attribute the difference in the value of TVR to these reasons.

\section{Limitations}

Our study has limitations that warrant 
consideration. First, this was a single-center observational study with a small number of patients. A multi-center study involving more patients could have more significant results and data. Second, our results may not apply to patients with renal insufficiency since they were not included.

\section{CONCLUSION}

Double high-dose intracoronary bolus tirofiban regimen in STEMI patients undergoing primary PCIwas associated withsignificantly lower 30-day TVR rates without an increase in bleeding events. However, it did not significantly affect MACE and allcause mortality rates.

\section{Conflict of interest}

The authors disclosed no conflict of interest during the preparation or publication of this manuscript.

\section{Financing}

The authors disclosed that they did not receive any grant during conduction or writing of this study.

\section{REFERENCES}

1. Meier P, Lansky AJ, Baumbach A. Almanac 2013: acute coronary syndromes. Heart 2013;99:1488-93.

2. Ward MJ, Kripalani S, Zhu Y, Storrow AB, Dittus RS, Harrell FE, Jr., et al. Incidence of emergency department visits for STelevation myocardial infarction in a recent six-year period in the United States. Am J Cardiol 2015;115:167-70.

3. Simes RJ, Topol EJ, Holmes DR, Jr., White HD, Rutsch WR, Vahanian A, et al. Link between the angiographic substudy and mortality outcomes in a large randomized trial of myocardial reperfusion. Importance of early and complete infarct artery reperfusion. GUSTO-I Investigators. Circulation 1995;91:19238.

4. Madan M, Berkowitz SD, Tcheng JE. Glycoprotein IIb/IIIa integrin blockade. Circulation 1998;98:2629-35.

5. Lynch JJ, Jr., Cook JJ, Sitko GR, Holahan MA, Ramjit DR, Mellott MJ, et al. Nonpeptide glycoprotein IIb/IIIa inhibitors. 5. Antithrombotic effects of MK-0383. J Pharmacol Exp Ther 1995;272:20-32.

6. Cutlip DE, Ricciardi MJ, Ling FS, Carrozza JP, Jr., Dua V, Garringer J, et al. Effect of tirofiban before primary angioplasty on initial coronary flow and early ST-segment resolution in patients with acute myocardial infarction. Am J Cardiol 2003;92:977-80.
7. De Luca G, Smit JJ, Ernst N, Suryapranata H, Ottervanger JP, Hoorntje JC, et al. Impact of adjunctive tirofiban administration on myocardial perfusion and mortality in patients undergoing primary angioplasty for ST-segment elevation myocardial infarction. Thromb Haemost 2005;93:820-3.

8. Shen J, Zhang Q, Zhang RY, Zhang JS, Hu J, Yang ZK, et al. Clinical benefits of adjunctive tirofiban therapy in patients with acute ST-segment elevation myocardial infarction undergoing primary percutaneous coronary intervention. Coron Artery Dis 2008;19:271-7.

9. Kaymaz C, Keles N, Ozdemir N, Tanboga IH, Demircan HC, Can MM, et al. The effects of tirofiban infusion on clinical and angiographic outcomes of patients with STEMI undergoing primary PCI. Anatol J Cardiol 2015;15:899-906.

10. Valgimigli M, Percoco G, Malagutti P, Campo G, Ferrari F, Barbieri D, et al. Tirofiban and sirolimus-eluting stent vs abciximab and bare-metal stent for acute myocardial infarction: a randomized trial. JAMA 2005;293:2109-17.

11. Van't Hof AW, Ten Berg J, Heestermans T, Dill T, Funck RC, van Werkum W, et al. Prehospital initiation of tirofiban in patients with ST-elevation myocardial infarction undergoing primary angioplasty (On-TIME 2): a multicentre, double-blind, randomised controlled trial. Lancet 2008;372:537-46.

12. Ulus T, Senol U, Tahmazov S, Iskenderov K, Mutlu F, Cavusoglu Y. High-dose bolus tirofiban versus low-dose bolus in patients with acute coronary syndrome undergoing percutaneous coronary intervention. Turk Kardiyol Dern Ars 2017;45:126-33.

13. Gibson CM, Jennings LK, Murphy SA, Lorenz DP, Giugliano RP, Harrington RA, et al. Association between platelet receptor occupancy after eptifibatide (integrilin) therapy and patency, myocardial perfusion, and ST-segment resolution among patients with ST-segment-elevation myocardial infarction: an INTEGRITI (Integrilin and Tenecteplase in Acute Myocardial Infarction) substudy. Circulation 2004;110:679-84.

14. Wu TG, Zhao Q, Huang WG, Wei JR, Chen SW, Zhao J, et al. Effect of intracoronary tirofiban in patients undergoing percutaneous coronary intervention for acute coronary syndrome. Circ J 2008;72:1605-9.

15. Kirma C, Erkol A, Pala S, Oduncu V, Dundar C, Izgi A, et al. Intracoronary bolus-only compared with intravenous bolus plus infusion of tirofiban application in patients with ST-elevation myocardial infarction undergoing primary percutaneous coronary intervention. Catheter Cardiovasc Interv 2012;79:59-67.

16. Sorajja P, Gersh BJ, Costantini C, McLaughlin MG, Zimetbaum P, Cox DA, et al. Combined prognostic utility of STsegment recovery and myocardial blush after primary percutaneous coronary intervention in acute myocardial infarction. Eur Heart J 2005;26:667-74.

17. Gibson CM, de Lemos JA, Murphy SA, Marble SJ, McCabe $\mathrm{CH}$, Cannon $\mathrm{CP}$, et al. Combination therapy with abciximab reduces angiographically evident thrombus in acute myocardial infarction: a TIMI 14 substudy. Circulation 2001;103:2550-4.

18. Mehran R, Rao SV, Bhatt DL, Gibson CM, Caixeta A, Eikelboom J, et al. Standardized bleeding definitions for cardiovascular clinical trials: a consensus report from the Bleeding Academic Research Consortium. Circulation 
2011;123:2736-47.

19. Lincoff AM, Popma JJ, Ellis SG, Hacker JA, Topol EJ. Abrupt vessel closure complicating coronary angioplasty: clinical, angiographic and therapeutic profile. J Am Coll Cardiol 1992;19:926-35.

20. Willerson JT. Inhibitors of platelet glycoprotein IIb/IIIa receptors. Will they be useful when given chronically? Circulation 1996;94:866-8.

21. Scarborough RM, Kleiman NS, Phillips DR. Platelet glycoprotein IIb/IIIa antagonists. What are the relevant issues concerning their pharmacology and clinical use? Circulation 1999;100:437-44.

22. Peerlinck K, De Lepeleire I, Goldberg M, Farrell D, Barrett J, Hand E, et al. MK-383 (L-700,462), a selective nonpeptide platelet glycoprotein IIb/IIIa antagonist, is active in man. Circulation 1993;88:1512-7.

23. Ernst NM, Suryapranata H, Miedema K, Slingerland RJ, Ottervanger JP, Hoorntje JC, et al. Achieved platelet aggregation inhibition after different antiplatelet regimens during percutaneous coronary intervention for ST-segment elevation myocardial infarction. J Am Coll Cardiol 2004;44:1187-93.

24. Van Werkum JW, Gerritsen WB, Kelder JC, Hackeng CM, Ernst SM, Deneer VH, et al. Inhibition of platelet function by abciximab or high-dose tirofiban in patients with STEMI undergoing primary PCI: a randomised trial. Neth Heart J 2007; 15:375-81.

25. Tang X, Li R, Jing Q, Liu Y, Liu P. Efficacy and Safety of Intracoronary versus Intravenous Administration of Tirofiban during Percutaneous Coronary Intervention for Acute Coronary Syndrome: A Meta-Analysis of Randomized Controlled Trials. PLoS One 2015;10:e129718.

26. Ibanez B, James S, Agewall S, Antunes MJ, Bucciarelli-Ducci C, Bueno H, et al. 2017 ESC Guidelines for the management of acute myocardial infarction in patients presenting with STsegment elevation: The Task Force for the management of acute myocardial infarction in patients presenting with ST-segment elevation of the European Society of Cardiology (ESC). Eur
Heart J 2018;39:119-77.

27. Budaj A, Brieger D, Steg PG, Goodman SG, Dabbous OH, Fox KA, et al. Global patterns of use of antithrombotic and antiplatelet therapies in patients with acute coronary syndromes: insights from the Global Registry of Acute Coronary Events (GRACE). Am Heart J 2003;146:999-1006.

28. Mandelzweig L, Battler A, Boyko V, Bueno H, Danchin N, Filippatos G, et al. The second Euro Heart Survey on acute coronary syndromes: characteristics, treatment, and outcome of patients with ACS in Europe and the Mediterranean Basin in 2004. Eur Heart J 2006;27:2285-93.

29. Schneider DJ, Herrmann HC, Lakkis N, Aguirre F, Wan Y, Aggarwal A, et al. Enhanced early inhibition of platelet aggregation with an increased bolus of tirofiban. Am J Cardiol 2002;90:1421-3.

30. De Luca G, Gibson CM, Bellandi F, Murphy S, Maioli M, Noc M, et al. Early glycoprotein IIb-IIIa inhibitors in primary angioplasty (EGYPT) cooperation: an individual patient data meta-analysis. Heart 2008;94:1548-58.

31. Ellis SG, Tendera M, de Belder MA, van Boven AJ, Widimsky P, Janssens L, et al. Facilitated PCI in patients with ST-elevation myocardial infarction. $\mathrm{N}$ Engl $\mathrm{J}$ Med 2008;358:2205-17.

32. Lee DP, Herity NA, Hiatt BL, Fearon WF, Rezaee M, Carter $\mathrm{AJ}$, et al. Adjunctive platelet glycoprotein IIb/IIIa receptor inhibition with tirofiban before primary angioplasty improves angiographic outcomes: results of the TIrofiban Given in the Emergency Room before Primary Angioplasty (TIGER-PA) pilot trial. Circulation 2003;107:1497-501.

33. Rao SV, O'Grady K, Pieper KS, Granger CB, Newby LK, Van de Werf F, et al. Impact of bleeding severity on clinical outcomes among patients with acute coronary syndromes. Am J Cardiol 2005;96:1200-6.

34. Stone GW, Bertrand ME, Moses JW, Ohman EM, Lincoff $\mathrm{AM}$, Ware $\mathrm{JH}$, et al. Routine upstream initiation vs deferred selective use of glycoprotein IIb/IIIa inhibitors in acute coronary syndromes: the ACUITY Timing trial. JAMA 2007;297:591-602. 